\title{
A COGESTÃO COMO INSTRUMENTO DE CONCRETIZAÇÃO DA FUNÇÃO SOCIAL DA EMPRESA
}

\author{
Elizabet Leal Silva* \\ Fábio Siebeneichler Andrade**
}

SUMÁRIO: Introdução; 2 A Função Social da Empresa e o Direito do Trabalbo; 3 Cogestão - Aspectos Históricos no Direito Estrangeiro; 4 Cogestão no Direito Brasileiro; 5 Considerações finais; Referências.

RESUMO: O objetivo do presente artigo é apresentar o instituto da cogestão como um instrumento que permitirá à empresa efetivamente cumprir sua função social. Para tanto surge a problemática de como a cogestão deve ser trabalhada para que atinja a finalidade almejada. Desta forma tem-se como hipótese a necessária participação dos trabalhadores nas decisões importantes da empresa de maneira mais direta, facilitando a institucionalização da sua função social. Reconhece-se que não é tarefa nada fácil, pois não faz parte da cultura empresarial brasileira ter os trabalhadores como partícipes de suas decisões e até mesmo de suas gestões. Portanto tal tema tem especial relevância quando se trata de estabelecer cada vez mais um equilíbrio na relação de trabalho, fundada basicamente na subordinação. Para o desenvolvimento da presente pesquisa utilizou-se o método dedutivo, pautado na técnica de pesquisa bibliográfica.

PALAVRAS-CHAVE: Cogestão; Empresa; Função Social; Trabalho.

\section{CO-MANAGEMENT AS A TOOL OF MATERIALIZING THE COMPANY'S SOCIAL ROLE}

\begin{abstract}
Current article investigates co-management as a tool for the fulfillment of a company's social role. The issue as how co-management should be coped with to meet its ends is highly important. The necessary and direct participation of workers in important decisions of the firm should be investigated for the institutionalization of their social role. This is not an easy task since it is uncommon in Brazil to admit the participation and administration of workers in Brazilian entrepreneurship. Current theme is relevant when one tries to keep a balance based on subordination. The deductive method based on bibliographical research has been employed.

Doutoranda no programa de pós-graduação em Direito pela Pontifícia Universidade Católica do Rio Grande do Sul (PUCRS); Bolsista Capes; E-mail: lealfeliz@hotmail.com.

** Doutor em Direito pela Universidade de Regensburg - Alemanha; Docente titular de Direito Civil da Pontifícia Universidade Católica do Rio Grande do Sul (PUCRS). Advogado em Porto Alegre (RS), Brasil.
\end{abstract}


KEY WORDS: Co-management; Enterprise; Social function; labor.

\section{LA COGESTIÓN COMO INSTRUMENTO DE CONCRETIZACIÓN DE LA FUNCIÓN SOCIAL DE LA EMPRESA}

RESUMEN: E objetivo del presente artículo es presentar el instituto de la cogestión como un instrumento que permitirá a la empresa efectivamente cumplir su función social. Para tanto surge la problemática de como la cogestión debe ser estructurada para que alcance la finalidad deseada. De esta forma se tiene como hipótesis la necesaria participación de los trabajadores en las decisiones importantes de la empresa de manera más directa, facilitando la institucionalización de su función social. Se reconoce que no es tarea nada fácil, pues no hace parte de la cultura empresarial brasileña tener los trabajadores como partícipes de sus decisiones e incluso de sus gestiones. Por lo tanto, tal tema tiene especial relevancia cuando se trata de establecer cada vez más un equilibrio en la relación laboral, fundada básicamente en la subordinación. Para el desarrollo de la presente investigación se utilizó el método deductivo, pautado en la técnica de investigación bibliográfica.

PALABRAS CLAVE: Cogestión; Empresa; Función Social; Trabajo.

\section{INTRODUÇÃO}

Não é de hoje que o cenário laboral tem se mostrado cada vez mais aberto às mudanças, sejam elas para garantir o equilíbrio e a paz nas relações de trabalho, sejam para garantir os direitos do trabalhador ou ainda para sustentar os interesses da classe patronal.

As necessidades atuais exigem que se estabeleçam parcerias entre os sujeitos da relação de trabalho, para atender aos anseios de ambos: da parte dos empregados e trabalhadores em geral, a garantia de seus direitos e melhorias das condições de trabalho e, da parte dos empregadores, a manutenção da sua atividade com a conquista dos lucros almejados e sua permanência cada vez mais sólida no mundo da concorrência.. 
A empresa hoje, diante da perspectiva organizativa traçada pelo texto constitucional de 1988, como se compreende a partir da análise do art. $170^{03}$, em que se estabelecem as diretrizes e os princípios da ordem econômica no ordenamento jurídico nacional, constitui-se no cerne da constituição econômica reguladora da concepção de mercado no Brasil ${ }^{04}$.

A primeira questão que surge em face da orientação traçada pela Constituição econômica nacional consiste em saber se a noção de função social deveria sobreporse ao interesse individual. Em princípio, a resposta deve ser negativa, pois a função social da empresa não pretende neutralizar todas as consequências que decorrem do princípio da livre iniciativa. Esse princípio liberal é perfeitamente compatível com os postulados da função social, impondo-se à doutrina e à jurisprudência específicas a ponderação e harmonização sobre estes dois polos de interesse.

Uma segunda esfera de questionamento consiste em saber quais são os efeitos que se extraem da concepção da função social da empresa. Tendo-se presente que esta noção deve ser concretizada, há que se verificar como ela se espraia no âmbito infraconstitucional. A este respeito, não obstante o Código Civil - CC não contemple expressamente à função social, tem nítida vinculação à Constituição, merecendo, porém, referência à existência de iniciativa parlamentar - Projeto de Lei 6.960/02 (Projeto Fiúza) - que pretende incluir um $\$ 2^{\circ}$ ao art. 966 do CC, a fim de incorporar o princípio da função social da empresa no diploma civil ${ }^{05}$.

03 "Art. 170: A ordem econômica, fundada na valorização do trabalho humano e na livre iniciativa, tem por fim assegurar a todos existência digna, conforme os ditames da justiça social, observados os seguintes princípios:

I. soberania nacional;

II - propriedade privada;

III. função social da propriedade;

Iv - livre concorrência;

$v^{v}$ - defesa do consumidor;

v - defesa do meio ambiente, inclusive mediante tratamento diferenciado conforme o informe ambiental dos produtos e serviços e de seus processos de elaboração e prestação;

VII - redução das dificuldades regionais e sociais;

VIII - busca do pleno emprego;

Ix - tratamento favorecido para as empresas de pequeno porte constituídas sob as leis brasileiras e que tenham sua sede e administração no país. Parágrafo único. É assegurado a todos o livre exercício de qualquer atividade econômica, independentemente de autorização de órgãos públicos, salvo nos casos previstos em lei".

${ }^{04}$ Sobre a relação entre ordem jurídica e mercado, ver, por exemplo, Natalino Irti. L'Ordine giuridico del Mercato. Laterza, 2009, p. 3 e segs.

${ }^{05}$ Art. 966, $\S 2^{\circ}$ : "O exercício da atividade de empresário, fundada na valorização do trabalho humano e na livre iniciativa, observará os limites impostos pelo seu fim econômico e social, pela boa fé e pelos bons costumes”. 
Em relação a este ponto, há que se ressaltar que a função social da empresa pode contribuir primeiramente para a preservação da empresa - como demonstram as diversas questões relativas à figura da recuperação judicial ${ }^{06}$.

Mas um outro feixe de irradiação do princípio da função social da empresa consiste na implementação de deveres externos. Com efeito, não se desconhece a percepção de que a função social da empresa pode ser reconhecida na realização do lucro, que se distribui aos acionistas, a partir do qual se vislumbra a distribuição de riqueza para os que tiveram a iniciativa de empreender. A ideia de que a função social seria atingida pelo atendimento de interesses privados há que ser levada em consideração, pois, em certa medida, está amparada no texto constitucional no indicado artigo 170 que reconhece e estimula a livre iniciativa.

Identifica-se também, que a empresa por intermédio de seus gestores, tem sua responsabilidade ampliada sendo que esta abrange os setores internos da companhia. Práticas como a de conflitos de interesses são vedadas e podem ser reputadas como ilícitas e implicar consequências jurídicas aos administradores.

Contudo, mesmo tendo-se presente que gerar lucros seja o objetivo central da empresa, há que ter-se claro que o princípio da função social da empresa pressupõe igualmente uma carga de concretização, de efetividade frente a terceiros, em face do que também se contempla na disciplina do artigo 170 da Constituição Federal, não se podendo presumir que a função social da empresa seria identificada somente com a indicada distribuição do lucro e a consequente riqueza distribuída aos que estão a ela diretamente vinculados, ou mesmo, com a simples prática de atos beneméritos ou ações humanitárias.

Nesse quadro, o objetivo do presente trabalho consiste em verificar a possibilidade de participação dos trabalhadores na gestão da empresa, tal instituto previsto no direito brasileiro, porém ainda não regulamentado. Procurar-se-á mostrar que este já existe em outros países, a longa data, de forma que poderia perfeitamente funcionar no Brasil. Tratar-se-á aqui a participação na modalidade da cogestão.

Neste sentido é que o presente trabalho será desenvolvido. Desta forma, no primeiro ponto será tratada de forma ampla a função social da empresa. O segundo ponto do trabalho consistirá na abordagem da função social da empresa e o direito

\footnotetext{
${ }^{06}$ Sobre o tema, ver, por exemplo, André Fernandes Estevez, Influências do princípio da preservação da empresa no direito falimentar: critérios sobre o plano de recuperação judicial. In: Estudos de Direito Empresarial (André Esteves/Márcio Felix Jobim. Saraiva, 2012, p. 574.
} 
do trabalho, visto que este está intimamente ligado ao âmbito empresarial. Em seguida far-se-á uma abordagem do instituto da cogestão, e seus aspectos históricos no direito estrangeiro. Na sequência será dada atenção ao instituto da cogestão no direito pátrio, e ao final verificar-se-á se existe relação deste com o cumprimento da função social da empresa no Brasil.

\section{A FUNÇÃO SOCIAL DA EMPRESA E O DIREITO DO TRABALHO}

Consoante acima indicado, a concepção de que a empresa tem a finalidade de obtenção do lucro concilia-se com a noção de que este centro de imputação negocial possui deveres na esfera social. $O$ fato de a empresa ter assumido por vontade própria ou não a responsabilidade para com a sociedade, fez com que se estabelecesse em especial com a classe trabalhadora uma relação de certa reciprocidade e cooperação.

A empresa, como centro de imputação de negócios ${ }^{07}$, tende a ser um dos principais espaços onde se estabelecem as relações laborais, e se insere como apta a assumir um novo papel neste contexto, vez que sua responsabilidade vai além de manter as relações, e alcançar o lucro esperado.

Não se configura mais apenas a relação de permanente dependência do trabalhador em relação ao empregador, mas uma via de duas mãos, na qual a empresa deve preocupar-se com os interesses convergentes existentes, a fim de que possa atender e cumprir a sua função social. Nesse desiderato, convém destacar que mesmo esse pensamento não fez com que as relações de trabalho ficassem livres dos conflitos que lhe são peculiares.

Referendando tal compreensão é possível adotar preleção de Fabio Konder Comparato quando diz que "o poder-dever do proprietário de dar à coisa uma destinação compatível com o interesse da comunidade transmuda-se, quando tais bens são incorporados a uma exploração empresarial, em poder-dever do titular do controle de dirigir a empresa para a realização dos interesses coletivos" ${ }^{\prime 08}$.

De acordo com Antônio Álvares da Silva, nesta perspectiva, "a empresa não é vista pelo trabalhador apenas como um meio pelo qual garante sua existência através do salário e o empregado não é visto pelo empregador apenas como um instrumento da produção, um mero custo de sua atividade produtiva" ${ }^{09}$. Mas, é

\footnotetext{
${ }^{07}$ Cf. Clóvis do Couto e Silva. O Conceito de Empresa no Direito Brasileiro. In: Revista Ajuris, v. 37, p. $42-43$.

${ }^{08}$ COMPARATO, Fabio Konder. Direito empresarial. São Paulo: Saraiva, 1995, p. 34.

${ }_{09}$ SILVA, Antônio Álvaro. Cogestão no estabelecimento e na empresa. São Paulo: LTr, 1991, p. 25.
} 
sabido que, nem sempre se tem essa compreensão nem por parte do trabalhador, nem tão pouco do empregador.

Não se pode negar que para atender sua função social, diante do Direito do trabalho a empresa teve que assumir uma postura mais de reserva, ou seja, não abriu mão do fato geração de lucro, até porque ele é essencial à sua permanência no mercado, mas passou a adotar medidas que visem não só respaldar sua obrigação estabelecida contratualmente, com o "sinalagma direito x dever", mas com fatores que proporcionam desenvolver a relação de trabalho a fim de satisfazer melhor os anseios e necessidades de seus empregados, como, por exemplo, oferecer melhores condições ao ambiente de trabalho.

De acordo com Anselmo Domingos da Paz Junior, ao tratar da questão social da empresa, relacionada ao Direito do Trabalho, na pós-modernidade a centralização do pensamento está justamente na busca do equilíbrio entre a propriedade e seus fins sociais, como "a empregabilidade, mobilidade de capital e das empresas de um País para outro, com o consequente conteúdo econômico decorrente de tais situações"10. Ainda nesse sentido o autor afirma que "a função social da empresa possui no Direito do trabalho uma relevância primordial para consecução da Justiça Social, objeto último do Direito seja quanto ao aspecto econômico, seja quanto ao aspecto de proteção da dignidade humana"11.

De acordo com Mozart Victor Russomano, os componentes que formam a empresa permanecem os mesmos, porém ocorreu uma mudança na importância dos papéis que cada um assumiu no cenário do mundo do capital. Como afirma a seguir:

na empresa moderna e democrática, em termos de democracia do trabalho (que, no nosso conceito, é a democracia política somada à democracia econômica), o trabalhador é personagem de um grande movimento, através do qual ele, realmente invade, de modo pacífico, setores que lhe eram vedados, como se fossem clausuras invioláveis. O que se chama a democratização da empresa privada, no fundo, apenas, é um processo de crescente participação do trabalhador na tessitura interna da empresa - pessoalmente e através das comissóes e conselhos internos - de modo a ter voz ativa nas resoluções de que depende o destino do empreendimento ${ }^{12}$.

\footnotetext{
${ }^{10}$ DA PAZ JUNIOR, Anselmo Domingos. A função social da empresa como um princípio do direito do trabalho pós-moderno. São Paulo: PUCSP, 2007. Dissertação, Pontifícia Universidade Católica de São Paulo, 2007, p. 138-139.

${ }^{11}$ Idem, ibidem, p. 145.

${ }^{12}$ RUSSOMANO, Mozart Victor. 9. ed. Curitiba: Juruá, 2004, p. 416.
} 
Partindo deste preceito, cumpre reconhecer que a função social de empresa é desempenhada em grande medida pela geração de empregos e pela possibilidade de pessoas humanas - empregados - nele desenvolverem aspectos de sua personalidade, realizando-se profissionalmente.

Não obstante, é indiscutível que o direito brasileiro estabeleceu uma expressiva disciplina acerca das relações de trabalho, alcançando também aspectos relativos aos direitos da personalidade do trabalhador, no âmbito do presente trabalho cumpre pontuar que um dos temas mais emblemáticos relacionados à estrutura do poder da empresa ainda não foi objeto de expressivo desenvolvimento no ordenamento nacional.

A cogestão está disciplinada no artigo $7^{\circ}, \mathrm{XI}^{13}$, e no 158 , da Constituição Federal ${ }^{14}$. Trata-se de tema indissoluvelmente ligado à visão já referida da empresa como organização, em que se destaca a concepção de que há relativa distensão na estrutura de poder da empresa, na medida em que não somente os proprietários, ou mesmo os administradores, mas também os trabalhadores, integram a estrutura dirigente.

Reputa-se que a presença do trabalhador na gestão da empresa é fundamental para o estabelecimento de relações de trabalho mais equilibradas e democráticas. A empresa deve estar ciente de que não pode sobreviver agindo como se o trabalhador não fosse essencial para a empresa, de acordo com Elizabet Leal da Silva, visando esse novo cenário,

a proposta de participação na gestão da empresa pode representar o novo caminho a ser trilhado pelo Direito do Trabalho, pois as próprias Constituições brasileiras, já se manifestaram expressamente sobre a participação dos trabalhadores nos lucros da empresa, o que falta é tornar a participação na gestão também uma condição expressa $a^{15}$.

A possibilidade real da participação dos trabalhadores na gestão da empresa possibilitaria o estabelecimento de relações mais harmoniosas no ambiente de

${ }^{13}$ Art. 7, XI: "São direitos dos trabalhadores urbanos e rurais, além de outros que visem à melhoria de sua condição social: [...] participação nos lucros, ou resultados, desvinculada da remuneração, e, excepcionalmente, participação na gestão da empresa, conforme definido em lei;

${ }^{14}$ Art. 158. "A Constituição assegura aos trabalhadores os seguintes direitos, além de outros que, nos termos da lei, visem à melhoria, de sua condição social: [...] V - integração do trabalhador na vida e no desenvolvimento da empresa, com participação nos lucros e, excepcionalmente, na gestão, nos casos e condições em que forem admitidos".

15 SILVA, Elizabet Leal. Emancipação do trabalhador e dignidade no trabalho. Porto Alegre: Sergio Antonio Fabris, 2011, p. 118. 
trabalho, uma vez tendo maior chance de opinar e até mesmo ajudar a encontrar saídas para os problemas que surgem no âmbito administrativo da empresa, os conflitos que acabam existindo por falta de confiança muitas vezes do trabalhador em relação às intenções e ações do empregador poderiam não existir.

Neste sentido, incumbiu ao Estado intervir de forma a "garantir uma 'justiça do mercado' e para tornar possível uma autêntica e livre concorrência, teve que intervir também para garantir o equilíbrio da relação econômica, social e jurídica do empregado e do empregador"16.

$\mathrm{Na}$ tentativa de tornar esta relação ainda mais equilibrada, o legislador brasileiro contemplou, no texto constitucional, mecanismos que sugerem uma maior parceria entre empregado e empregador, entre eles estão a participação nos lucros e excepcionalmente a participação na gestão da empresa, previsão constante do artigo $7^{\circ}$, XI da CFRB/88.

A partir deste ponto, a presente pesquisa tratará da participação na gestão na modalidade de cogestão, com maior atenção, por ser ponto central para o presente trabalho, iniciando por uma abordagem histórica do presente instituto, ainda não regulamentado no Brasil.

\section{COGESTÃO - ASPECTOS HISTÓRICOS NO DIREITO ESTRANGEIRO}

Historicamente o instituto da participação na gestão já vem sendo difundido há muito tempo. Por volta de 1846, na França quando da criação do primeiro conselho de empresa com representantes nos seus diversos setores. Em 1917, foram instituídos os delegados nas fábricas de armamentos, pelo então ministro de Armamentos da França, Albert Thomas, que se tornou o primeiro diretor da OIT. A participação do trabalhador na gestão da empresa também foi preocupação manifestada pela igreja Católica por meio da Encíclica Mater et Magistra, de autoria do Papa João XXIII, a qual defendia que os trabalhadores fizessem parte nas empresas, porém esta participação deveria ser regulada por lei específica ${ }^{17}$.

Em muitos países a cogestão, ou participação dos trabalhadores na empresa, já é praticada como um instrumento essencial para a manutenção da relação de

${ }_{16}$ SILVA, Elizabet Leal. Emancipação do trabalhador e dignidade no trabalho. Porto Alegre: Sergio Antonio Fabris, 2011, p. 262.

${ }^{17}$ MARTINS, Sérgio Pinto. Direito do trabalho. 13. ed., rev. e ampl., atualizada até dezembro de 2000. São Paulo: Atlas, 2001, p. 679. 
trabalho. Constituições como de Portugal (1976), Equador (1978), Peru (1979), e Noruega (1980), possuem em seu texto o direito de participação dos trabalhadores nas empresas ${ }^{18}$.

$\mathrm{Na}$ Alemanha a participação se deu inicialmente com os comitês de fábricas que foram criados de maneira facultativa no Código Industrial de 1891. Durante a primeira guerra mundial, os mesmos comitês foram criados de forma obrigatória em todas as empresas com mais de 50 funcionários. Já em 1919, a Constituição de Weimar previu a criação dos "conselhos de trabalhadores nas empresas, nos distritos e no Reich, além de um conselho econômico nacional"19.

$\mathrm{Na}$ Inglaterra, os chamados comitês de empresa foram criados ainda no período da primeira guerra mundial, com composição paritária, denominados de comitês Whiltey. Em 1919, o tema foi abordado também na Áustria, que acabou legislando a respeito dos conselhos de empresa. A Rússia foi outro país que também legislou a respeito da participação dos empregados nas empresas; aqui, os comitês tinham atribuições diversas e foram posteriormente unidos aos sindicatos formando assim a base da hierarquia sindical. Estes foram, portanto, os primeiros acenos sobre a possibilidade da participação dos trabalhadores na gestão das empresas ${ }^{20}$.

Ao final da segunda guerra mundial, o tema foi retomado ainda com mais força, em especial nos países europeus como o caso da França e da Alemanha, países em que os sistemas legislativos merecem destaque no tema. Na França "a caracterização deu-se em especial pelo preâmbulo da Constituição que previu que a participação dos trabalhadores se daria pela representação de seus delegados, da determinação das convenções coletivas de trabalho e da gestão das empresas" ${ }^{21}$.

Já na Alemanha Ocidental a cogestão compreendeu a participação dos trabalhadores nas diretorias e conselhos de vigilâncias, que eram compostos de representantes acionistas e trabalhadores em igual número, e estes elegiam uma terceira pessoa independente para presidir o conselho. Oficialmente o "movimento foi implantado em 14 de abril de 1951, para o setor mineiro e metalúrgico, após reivindicações da confederação dos sindicatos, na tentativa de gerar maiores satisfações aos trabalhadores com maiores benefícios aos dirigentes"22.

\footnotetext{
18 Idem, ibidem, p. 680 .

19 SUSSEKIND, Arnaldo. Direito constitucional do trabalho. Rio de Janeiro: Renovar, 1999, p. 465.

${ }^{20}$ SILVA, Elizabet Leal. Emancipação do trabalhador e dignidade no trabalho. Porto Alegre: Sergio Antonio Fabris, 2011, p. 118.

${ }^{21}$ SUSSEKIND, Arnaldo. Direito constitucional do trabalho. Rio de Janeiro: Renovar, 1999, p. 467.

22 Idem, ibidem, p. 468.
} 
José Henrique Faria ${ }^{23}$ (1982) afirma que apenas em 1976 a chamada "mitbestimmung" foi regulamentada no sentido de atingir também outros setores da nação germânica. De forma que após inúmeras tentativas e discussões é que se chegou, no início de 1976, à uma regulamentação da cogestão que agradasse a todos os envolvidos na República Federal da Alemanha. A partir desta regulamentação garantiu-se a subsistência entre capital e trabalho na mesma empresa, viabilizando igualdade de direitos, e permitindo a participação dos empregados da produção nas decisões importantes.

Ao tratar do tema no âmbito do direito estrangeiro, não poderia deixar de citar a presença da OIT (Organização Internacional do Trabalho), pois é sabido que quando determinado tema é tratado sobre a ótica da OIT, ele toma vulto e repercussão muito mais ampla que apenas quando tratado no âmbito interno do ordenamento pátrio. Entendendo assim, verifica-se que mesmo existindo a Convenção 135, que trata da proteção e facilidades a conceder aos representantes dos trabalhadores na empresa, nada se efetivou em relação à cogestão. O que acaba não estimulando a criação de normas regulamentadoras, que implementem efetivamente esse instituto na estrutura legislativa interna, como é o caso do Brasil, que será tratado logo a seguir $^{24}$.

No âmbito internacional neste aspecto, existem apenas, segundo Arion Sayão Romita, "normas e instrumentos referentes à negociação e aos procedimentos de consulta e colaboração no interior das empresas, mas as experiências sobre participação na gestão ainda são escassas e não representam o grau de generalidade que justifique a aprovação de convenções ou recomendações sobre o assunto" ${ }^{25}$.

\section{COGESTÃO NO DIREITO BRASILEIRO}

No direito brasileiro, o referido instituto foi apresentado indiretamente por volta de 1944, quando do decreto 7.036 de 10 de novembro de 1944, que estabelecia regras instituindo comissões internas de acidentes de trabalho, com a finalidade de

\footnotetext{
${ }^{23}$ FARIA, José Henrique. Cogestão: uma nova instituição. Revista de Administração IA-USP, v. 17, n. 01, janeiro/ março, 1982. Disponível em: <www.rausp.br/busca/ artigo.asp?. num _ artigo=922>. Acesso em: 15 ago. 2015.

${ }^{24}$ SUSSEKIND, Arnaldo. Direito constitucional do trabalho. Rio de Janeiro: Renovar, 1999, p. 470.

${ }^{25}$ ROMITA, Arion Sayão. Direitos fundamentais nas relações de trabalho. 2. ed. rev. e aum. São Paulo: LTr, 2007, p. 365 .
} 
diminuir os acidentes nos referidos locais, surgindo assim a participação direta dos empregados, uma forma de cogestão ${ }^{26}$.

No texto constitucional pátrio a primeira vez em que a participação na gestão apareceu foi em 1967, no inciso IV do artigo 158 que tratava da "integração do trabalhador na vida e no desenvolvimento da empresa, com participação nos lucros e, excepcionalmente, na gestão, nos casos e condições que fossem estabelecidos"27. Em 1969, a Emenda Constitucional - EC n ${ }^{0} 01$ também tratou do tema, mas sem maiores definições, atribuindo à legislação a responsabilidade de decisão sobre como deveria ocorrer esta gestão.

Essas duas formas de participação permanecem na Constituição de 1988, no capítulo dos direitos sociais em seu artigo $7^{\circ}$, parágrafo XI, que assegura que um dos direitos dos trabalhadores urbanos e rurais para a melhoria da sua condição social é a "participação nos lucros, ou resultados desvinculados da remuneração, e, excepcionalmente, participação na gestão da empresa, conforme, definido em lei" ${ }^{\text {"28 }}$. Contudo é preciso destacar que não é comum no Brasil a participação de representantes da classe trabalhadora em conselhos de administração das empresas que lhes contrata ${ }^{29}$.

Embora presente no texto constitucional, a participação dos trabalhadores na gestão da empresa é tema bastante controverso. De forma que não se tem nem mesmo uma conformidade sobre como efetivamente esta poderia ocorrer. Como se verifica na afirmação de Arnaldo Sussekind, a seguir:

a participação dos empregados na gestão da empresa não significa, obrigatoriamente, participação em órgãos de decisão. Há vários níveis de participação. A própria cogestão não traduz, necessariamente, co-decisão. Segundo prevalece no direito comparado, essa participação pode corresponder a: a) funções meramente consultivas, consubstanciadas nas atribuições conferidas ao representante do pessoal ou a órgãos integrados por empregados, em representação exclusiva ou paritária; b) inclusão de empregados em comitês ou comissões internas, geralmente paritárias, encarregadas de velar pela prevenção dos infortúnios do trabalho, promover a conciliação dos

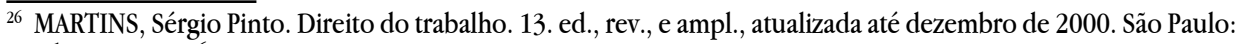
Atlas, 2001, p. 680.

${ }^{27}$ MARTINS, Sérgio Pinto. Direito do trabalho. 13. ed., rev., e ampl., atualizada até dezembro de 2000. São Paulo: Atlas, 2001, p. 680.

${ }^{28}$ BRASIL. Constituição da República Federativa do Brasil. Disponível em: < http://www.planalto.gov.br/ccivil_03/Constituicao/Constituicao.htm >. Acesso em: 10 mar. 2016.

${ }^{29}$ JORGE NETO, Francisco Ferreira; CAVALCANTE, Jouberto de Quadros Pessoa. Direito do trabalho. 4. ed. Rio de Janeiro: Lumen Juris, 2008. Tomo II, p. 1699.
} 
litígios individuais de caráter trabalhista ou gerir obras sociais, culturais, desportivas, programas de aprendizagem etc.; c) integração de representantes dos empregados, em paridade com os acionistas ou, minoritariamente, em órgãos com poder de decidir (co-decisão); d) autogestão da empresa ${ }^{30}$.

Ainda em âmbito legislativo, a participação dos trabalhadores na gestão da empresa mereceu tratamento mais pontual na Lei 10.303/2001, que modificou alguns artigos da Lei das Sociedades Anônimas.

A matéria passou a ser disciplinada pelo artigo 140, IV, em seu parágrafo único, "sendo estipulado que o estatuto da sociedade anônima poderá determinar a participação no conselho de representantes dos empregados, escolhidos pelo voto destes, em eleição direta, organizada pela empresa, em conjunto com as entidades sindicais que os representem" 31 .

A cogestão se configura na participação do empregado na tomada de decisões na empresa em parceria com o empregador, de forma a atuar na administração e gerenciamento da mesma. Ao definir a cogestão como forma de participação dos trabalhadores na administração da empresa não se pode confundi-la com a participação nos lucros, pois na participação dos lucros, o fundamento é que em existindo lucro, parte deste seja distribuído entre os empregados, já na participação da gestão a finalidade é que os trabalhadores possam opinar diretamente no próprio destino da empresa ${ }^{32}$.

$\mathrm{Na}$ cogestão a participação do empregado ocorre diretamente na direção da empresa, sendo diretamente responsável pelos riscos existentes e pela própria constatação ou não do lucro. "Porém, é inegável que a participação nos lucros é uma forma indireta de cogestão, a qual o empregado terá o interesse com a sua participação para que a empresa tenha lucros, já que estes serão rateados oportunamente com o conjunto de trabalhadores"33.

Não se confunde em essência, com a previsão contida no artigo 11 , da Constituição, que prevê a eleição nas empresas com mais de 200 empregados, de

\footnotetext{
$\overline{30}$ SUSSEKIND, Arnaldo. Direito constitucional do trabalho. Rio de Janeiro: Renovar, 1999, p. 492.

${ }^{31}$ FACCHINI NETO, Eugênio; ANDRADE, Fábio Siebeneichler. A funcionalização do direito: a empresa e sua função social. In: STEINDORFER, Fabriccio; MIZUTA, Alessandra. Limitações constitucionais ao exercício da atividade econômica. Curitiba: Juruá, 2016, p. 11-41.

32 MARTINS, Sérgio Pinto. Direito do trabalho. 13. ed., rev., e ampl., atual. até dezembro de 2000. São Paulo: Atlas, 2001.

${ }^{33}$ JORGE NETO, Francisco Ferreira; CAVALCANTE, Jouberto de Quadros Pessoa. Direito do trabalho. 4. ed. Rio de Janeiro: Lumen Juris, 2008, Tomo II, p. 1699.
} 
um representante dos empregados a fim de promover o entendimento direto com os empregadores.

Oportunamente ocorre ressaltar que a cogestão implica cooperação, evitando a oposição entre empregado e empregador, a fim de valorizar a relação entre capital e trabalho ${ }^{34}$. Neste sentido, é que se verifica a possibilidade do instituto da cogestão ser de extrema importância para o cumprimento efetivo da função social da empresa, vez que se mostra como um instrumento de participação que permitiria aos trabalhadores vincularem-se diretamente aos mecanismos de gestão, que buscam a manutenção da própria empresa com fim de sua manutenção, bem como da empregabilidade e garantias dos trabalhadores.

Verifica-se que, embora o instituto da cogestão esteja previsto na norma constitucional e também na infraconstitucional, em nada se configura a obrigatoriedade da existência deste no direito brasileiro, sendo, portanto, uma mera faculdade do empregador efetivar ou não tal modalidade, o que tem criado cada vez mais dificuldades para sua concretização. $O$ fato de configurar como uma norma programática, pendente de regulamentação torna sua concretização quase que uma utopia no cenário econômico atual.

Ademais, inexistem mecanismos de incentivo às sociedades que a adotem, a fim de que elas sejam incentivadas a, paulatinamente, alterar sua estrutura de poder. Nesse contexto, é perceptível que o modo como foi concretizada a figura da cogestão no ordenamento pátrio conduz à percepção de que inexistiu um efetivo esforço do legislador para o fim de introduzir uma mudança real no quadro da estrutura de poder da empresa.

Desse modo, observa-se que a função social da empresa opera em um patamar de baixa complexidade, reduzido ao papel de extensão de benefícios sociais, sem alterar efetivamente a estrutura da empresa, calcada em uma concepção hierárquica, de cima para baixo, que permanece consolidada.

\section{CONSIDERAÇÕES FINAIS}

Pelo exposto identificou-se que a empresa se configura na sociedade atual não mais apenas como um meio pelo qual seus proprietários almejem única

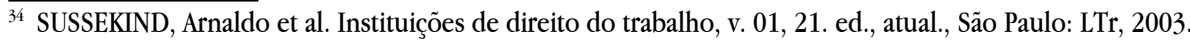


e exclusivamente o lucro. Contemporaneamente, seu papel na atual conjuntura econômica representa um instrumento de desenvolvimento social e, desta forma, deve preocupar-se em propiciar influxos para os terceiros com que se relaciona na esfera social.

Este novo posicionamento toma corpo a partir da discussão em torno da função social da propriedade e do contrato, que se estende à empresa, dando assim no atual contexto da sociedade uma perspectiva de ampliação e aproximação das relações existentes no âmbito empresarial, como, por exemplo, na esfera ambiental e no âmbito da sua relação com os consumidores.

No que concerne ao terceiro, pontifica a questão acerca dos deveres e forma de relacionamento que a empresa, centro de imputação negocial por excelência, deva ter com seus colaborais mais próximos, no caso os trabalhadores.

Desta forma, ao atender a sua função social a relação existente entre empregado e empregador não se configura apenas como uma relação de permanente dependência do trabalhador em relação ao empregador, mas uma via de duas mãos, na qual a empresa deve preocupar-se com os interesses convergentes existentes, a fim de que possa atender e cumprir a sua função social.

Nada mais salutar nesta linha, que os empregados, ou trabalhadores em geral, possam também dar sua contribuição direta à empresa, não apenas no cumprimento das atividades para as quais foram contratados, mas também nos momentos importantes de decisão da empresa, o que se configuraria em uma administração democrática no âmbito da empresa. Para tanto sugere-se o instituto da cogestão.

A cogestão como foi visto não é algo novo, ao contrário, há países que já a utilizam há cerca de 40 anos, e este vem se revelando como um instrumento de democratização no ambiente empresarial, e totalmente compatível com o princípio da função social. Verifica-se que com a participação direta dos trabalhadores nas decisões da empresa, maior será o desejo dos trabalhadores de que tudo dê certo.

Ao concluir este trabalho, verifica-se que, no Brasil, muito embora o instituto da cogestão esteja previsto na norma constitucional, no âmbito infraconstitucional, em nada se configura a obrigatoriedade da existência deste no direito brasileiro, na medida em que, de um lado, a matéria foi estrutura como sendo uma faculdade do empregador efetivar ou não tal modalidade.

Mediante esta forma de regulamentação, há que se ponderar acerca das 
extremas dificuldades para sua concretização. Afinal, a figura da cogestão lida com a estrutura de poder da empresa, sendo difícil de configurar que o empresário - como também como qualquer agente econômico ou social - se disporá, voluntariamente, a abdicar de sua esfera de poder para cedê-la a um terceiro.

Seria necessário que o legislador, ao regular a figura, implementasse mecanismos de incentivo - tributário, por exemplo - a fim de que o empresário fosse estimulado a seguir um caminho mais democrático de gestão no seio da empresa.

O fato, porém, de configurar-se a cogestão como uma modalidade facultativa passível de ser adotada apenas e tão-somente se houver a boa vontade do legislador, pode apontar para a reduzida intenção do ordenamento jurídico brasileiro para alterar efetivamente as estruturas de poder na ordem administrativa e negocial.

Nesse quadro, a visão de função social adotada no ordenamento jurídico brasileiro permanece ancorada em uma visão novecentista, do nascedouro do movimento sindical em que a preocupação maior era conceder benefícios patrimoniais ao empregado.

Verifica-se, portanto, que em face da ausência de uma regulamentação mais efetiva do tema, o mecanismo da cogestão pode permanecer uma utopia no cenário jurídico brasileiro. Urge, portanto, que se insista na matéria, a fim de que ela ingresse na realidade normativa e empresarial, de modo que paulatinamente a visão cooperativa se efetive, contribuindo para uma melhor regulação da vida do trabalho na esfera empresarial, ao que se configuraria em mais um instrumento de atendimento à função social da empresa.

\section{REFERÊNCIAS}

BRASIL. Constituição da República Federativa do Brasil. Disponível em: < http:// www.planalto.gov.br/ccivil_03/Constituicao/Constituicao.htm>. Acesso em: 10 mar. 2016.

COMPARATO, Fábio Konder. Direito empresarial. São Paulo: Saraiva, 1995.

DA PAZ JUNIOR, Anselmo Domingos. A função social da empresa como um princípio do direito do trabalho pós-moderno. 2007. Dissertação (mestrado) Pontifícia Universidade Católica de São Paulo, 2007. 
IA-USP, v. 17, n. 01, janeiro/março, 1982. Disponível em: <www.rausp.br/busca/ artigo.asp?. num_artigo=922>. Acesso em: 15 ago. 2015.

FRAZÃO, Ana. Função social da empresa: repercussões sobre a responsabilidade civil de controladores e administradores de S/As. Rio de Janeiro: Renovar, 2011.

MARTINS, Sérgio Pinto. Direito do trabalho, 13. ed., ver., e ampl. atual. até dezembro de 2000. São Paulo: Atlas, 2001.

FACCHINI NETO, Eugênio; ANDRADE, Fábio Siebeneichler. A funcionalização do direito: a empresa e sua função social. In: STEINDORFER, Fabriccio; MIZUTA, Alessandra. Limitaçóes constitucionais ao exercício da atividade econômica. Curitiba: Juruá, 2016, p. 11-41.

JORGE NETO, Francisco Ferreira; CAVALCANTE, Jouberto de Quadros Pessoa. Direito do trabalho. 4. ed. Rio de Janeiro: Lumen Juris, 2008. Tomo II.

ROMITA, Arion Sayão. Direitos fundamentais nas relações de trabalho. 2. ed. rev. e aum. São Paulo: LTr, 2007.

RUSSOMANO, Mozart Victor. 9. ed. Curitiba: Juruá, 2004.

SILVA, Antônio Álvares da. Cogestão no estabelecimento e na empresa. São Paulo: LTr, 1991.

SILVA, Elizabet Leal. Emancipação do trabalhador e dignidade no trabalho. Porto Alegre: Sergio Antonio Fabris, 2011.

SUSSEKIND, Arnaldo et al. Instituições de direito do trabalho, v. 01, 21. ed., atual., São Paulo: LTr, 2003.

SUSSEKIND, Arnaldo. Direito constitucional do trabalho. Rio de Janeiro: Renovar, 1999. 